\title{
Examining the Motivation of Beninese Advanced Students to Learn English and Spanish as Foreign Languages
}

\author{
Dr. TCHIBOZO LAINE Ida Marie Joséphine, Dr. KAKPO Marcel, \\ Dr. KPOHOUE Ferdinand
}

English Dpt./FLASH/UAC

\begin{abstract}
The purpose of this qualitative study was to examine the motivation of the advanced language learners of Spanish and English in Benin. To collect the data, a two part questionnaire was administered to 120 respondents randomly selected in different secondary schools. The most important findings of the study were the differences in integrative and extrinsic motivation. Actually, the participants were more interested in English than Spanish and thus the integrative motivation was stronger in English. The participants' motivation to learn both languages is more integrative than instrumental. Extrinsic motivation, on the other hand, is stronger in the Spanish language compared to English. Gender differences appeared in extrinsic and instrumental motivation towards English: girls were slightly more extrinsically motivated to learn English than boys, and boys had more instrumental motivation towards English. In Spanish, more girls than boys seem to acknowledge the value of Spanish in the future.
\end{abstract}

Keywords: Benin, Foreign language learners, motivation, English, Spanish.

\section{InTRODUCTION AND PURPOSE}

Even today, there is still the need to know more about motivation because contexts vary and times change. Although there are comparative studies on motivation (Dörnyei, 1994 and 2005; Virnes, 1995; Malmberg, 1994; Gardner and Lambert, 1972), there is a dearth of the literature as to comparisons between students' motivation to learn English and Spanish. In Benin, these two languages are some of the most commonly studied foreign languages. That is why the present study aims at investigating the motivation of Beninese advanced learners to learn English and Spanish as foreign languages. More specifically, it seeks to answer some of the following questions: 1) What motivates Beninese advanced learners to learn English and Spanish? 2) Are there differences in these learners' motivation to learn English and Spanish? 3) Are there gender differences in these learners' motivation?

\section{LiteratURE}

\subsection{Theories of Motivation}

Motivation is a concept which has been defined in many different ways in theories of language learning and it has been divided into different categories and further into subcategories. The two most common and well-known divisions seem to be 1) integrative and instrumental motivation presented by Gardner and Lambert (1972), Peacock (1998), Silverman (2000), McKay (2002), Banks (2003), Mertens (2005) as well as Stemler (2001) and 2) extrinsic and intrinsic motivation outlined by Ryan and Deci (2000).

A person with integrative motivation has a genuine interest in the language and people who speak it. Instrumental motivation, on the other hand, is characterized by a hope of improving one's social status and getting economic benefits by knowing a foreign language. In intrinsic motivation, action or learning neither has a separable consequence nor external pressure or rewards, but the reward is in the activity itself. This type of motivation is considered as present from birth onwards because people do things that interest them and by acting according to their interest, their skills and knowledge develop and grow. On its part, extrinsic motivation results in a separable outcome, which can be for example a good grade. 


\section{Dr. TCHIBOZO LAINE Ida Marie Joséphine et al.}

It can be said that integrative and intrinsic motivations are somewhat comparable to each other (Brown, 1987; Howatt, 2004; Heining-Boyton and Haitema, 2007; Lichtman, 2010), since both of them are characterized by a good interest in the target language and culture. The difference between them might be that integrative motivation is more far-reaching than intrinsic motivation, which may be concentrated on a single task. If a person is instrumentally motivated, his or her main objectives are social and economic benefits. An extrinsically motivated person rather focuses on rewards, grades and meeting expectations of other people.

\subsection{Variables that Influence Motivation}

For Malmberg and Little (2002:130), three main elements namely parents, teachers and the school environment have a lot of influence on students' motivation towards school subjects. In effect, teacher and parental expectations have the greatest influence on the development of a child's motivation either positively or negatively. The literature shows that competition, unfair treatment of students, rewards and evaluation, when used negatively as tools, can diminish students' motivation. School environment aspects such as evaluation become more important with each advanced level or class; and this, together with competition between students, have been estimated to reduce motivation (Tse, 2000; Crystal, 2001; Aunola, 2002; Savignon, 2002; Littlewood, 2010).

The goals of a student are also closely linked to motivation, since a goal is usually something that a person wants to achieve. Besides, accomplishments and success at school are connected to intrinsic motivation: a student who is successful at school has less external sources of motivation, unlike a weaker student has (Green, 1993; Malmberg and Little, 2002; Johnson and Onwuegbuzie, 2004; Price and Gascoigne, 2006; Kouritzin, Piquemal and Renaud, 2009). The researcher is in line with Aunola that the role of parents and teachers in a student's life is enormous, and their expectations and opinions about the importance of different school subjects affect the student either directly or indirectly. He believes that success at school certainly has a lot of influence on student's motivation: if a student is successful in some school subject, s/he gets positive feedback and positive experiences, which encourage him or her to continue studying the subject.

\subsection{Gender Differences}

It is usually thought that girls are more talented in languages than boys, and boys are more successful in sciences than girls. Although this seems to be an old myth, it still affects people's expectations about different talents between boys and girls. As Aunola (2002: 114) explains, the impressions about gender differences in school subjects affect the academic orientation of both boys and girls. As such, children are usually motivated to learn all the subjects during their first years at school; but later, their motivation begins to focus on different school subjects and it becomes more stable (Aunola, 2002: 111). In the researcher's experience, many students are interested in languages in general, but there might also be differences in students' interests towards different languages. For instance, a student might be very motivated to learn English but not at all interested in Spanish, or vice versa.

\section{Methodology}

The present study, unlike most studies of motivation, is qualitative. To collect the data, a two part questionnaire was administered in February 2015 to 120 respondents randomly selected in different secondary schools in the country. The main criteria were that respondents should be in literary classes, which means that they studied English and have to choose another foreign language among Spanish and German. In addition, an equal number of participants of both sexes (boys and girls) were used. It took them 10 to 20 minutes to complete the questionnaire. The return rate was $83,33 \%$ (i.e. 100 completed questionnaire were returned to the researcher).

The questionnaire consisted of two sections: The first section which consisted of questions based on scales included six statements, and the students were to circle the number that best corresponded to their feelings according to a Likert scale from one to five: 1 agree strongly, 2 agree somewhat, 3 neutral, 4 disagree somewhat, 5 disagree strongly. The statements that the participants were to answer according to the above-mentioned scale were the following:

\section{I am interested in the English/Spanish language and the cultures of English/Spanish-speaking countries}

\section{The English/Spanish language is important to me because I will need it in my future occupation}


Examining the Motivation of Beninese Advanced Students to Learn English and Spanish as Foreign Languages

3. I am studying English/Spanish because I want to be able to communicate with foreigners

4. I am studying English/Spanish only because I have to

5. I will need English/Spanish in the studies after secondary school

6. I want to learn English/Spanish because many employers require English/Spanish language skills

In the section two on open-ended questions, the participants were to answer if they would like to study English and Spanish after secondary school. Three most important reasons for studying English and Spanish were asked, as well as the reason why the languages are important to the participants. Moreover, the place or the situation where the participants think they are going need these languages was inquired. The last two open-ended questions were about the role of the school and the effect of activities outside school on language learning motivation.

Data of the study was analysed following Creswell (1994)' spiral analysis. Actually, answers were compared concerning motivation to learn English and motivation to learn Spanish. These answers were also grouped by gender and compared.

\section{Results}

Results are presented by language. Tables outline quantitative results while the most common answers to open-ended questions are presented after them.

\subsection{Motivation to Learn English}

\subsubsection{Statements on English}

Table1. Answers about English (Note: 1 agree strongly, 2 agree somewhat, 3 neutral, 4 disagree somewhat, 5 disagree strongly)

\begin{tabular}{|c|c|c|c|c|c|c|c|}
\hline & & & \multicolumn{5}{|c|}{ Likert-scale (\%) } \\
\hline $\mathrm{N}^{\circ}$ & STATEMENTS & & 1 & 2 & 3 & 4 & 5 \\
\hline \multirow{3}{*}{1} & \multirow{3}{*}{$\begin{array}{l}\text { I am interested in the English language and the cultures of English - } \\
\text { speaking countries }\end{array}$} & Total & 40 & 52 & 3 & 5 & 00 \\
\hline & & Girls & 48 & 43 & 5 & 4 & 00 \\
\hline & & Boys & 27 & 73 & 00 & 00 & 00 \\
\hline \multirow{3}{*}{2} & \multirow{3}{*}{$\begin{array}{l}\text { The English language is important to me because I will need it in my } \\
\text { future occupation }\end{array}$} & Total & 33 & 44 & 18 & 5 & 00 \\
\hline & & Girls & 37 & 37 & 20 & 6 & 00 \\
\hline & & Boys & 28 & 50 & 11 & 11 & 00 \\
\hline \multirow{3}{*}{3} & \multirow{3}{*}{$\begin{array}{l}\text { I am studying English because I want to be able to communicate with } \\
\text { foreigners }\end{array}$} & Total & 73 & 25 & 2 & 00 & 00 \\
\hline & & Girls & 72 & 22 & 6 & 00 & 00 \\
\hline & & Boys & 71 & 29 & 00 & 00 & 00 \\
\hline \multirow{3}{*}{4} & \multirow{3}{*}{ I am studying English only because I have to } & Total & 00 & 00 & 00 & 23 & 77 \\
\hline & & Girls & 00 & 00 & 00 & 20 & 80 \\
\hline & & Boys & 00 & 00 & 00 & 31 & 69 \\
\hline \multirow{3}{*}{5} & \multirow{3}{*}{ I will need English in the studies after secondary school } & Total & 52 & 36 & 12 & 00 & 00 \\
\hline & & Girls & 58 & 32 & 10 & 00 & 00 \\
\hline & & Boys & 43 & 43 & 14 & 00 & 00 \\
\hline \multirow{3}{*}{6} & \multirow{3}{*}{$\begin{array}{l}\text { I want to learn English because many employers require English } \\
\text { language skills }\end{array}$} & Total & 56 & 40 & 00 & 4 & 00 \\
\hline & & Girls & 64 & 32 & 00 & 4 & 00 \\
\hline & & Boys & 40 & 60 & 00 & 00 & 00 \\
\hline
\end{tabular}

The first percentage in each column in Table i shows the total percentage of answers to the questions, and the percentages of answers given by girls and boys are separated underneath the total percentage. The majority of the participants agreed somewhat with the claim "I am interested in the English language and the cultures of English-speaking countries" (52\%) and "The English language is important to me because I am will need it in my future occupation" (44\%). The communicative value of English is strong, which is demonstrated in the answers given by the participants: $73 \%$ agreed strongly with the claim "I am studying English because I want to be able to communicate with foreigners". No one disagreed with this claim, so the answers were very homogenous. Table $\mathrm{i}$ also illustrates that it is clear that most participants did not study English only because they were obliged to do so; on the contrary, $77 \%$ disagreed strongly with the claim "I am studying English only because I have to". What is more, English was considered useful in the studies after secondary school: 52\% 
agreed strongly with the claim "I will need English in the studies after secondary school". No one answered that they disagree with this claim. Last, 56\% answered that they agree strongly with the claim "I want to learn English because many employees require English language skills".

\subsubsection{Open-Ended Questions About English}

When asked about the things that motivate them to study English the most, answers were:

- For Boys:

- English is important/I will need English $60 \%$

- I need English when travelling/ communicating with people $55 \%$

- I need English in my future occupation $45 \%$

- For Girls:

- I need English when travelling/ communicating with people 70\%

- English is useful in the future $30 \%$

- I need English in my future occupation 25\%

- Examination/course exams $20 \%$

- For Both sexes:

- I need English when travelling/ communicating with people $65 \%$

- English is useful and important in the future $40 \%$

- I need English in my future occupation 35\%

So, the common answers were travelling and communication with foreigners, as well as the usefulness and the importance of the English language.

- When asked about the reason why English is important, comments were:

- For boys:

(1) English is everywhere; you hear and see it a lot.

(2) I watch programmes in English, read literature in English and use web sites in English.

- For girls:

(3) Many texts, books, movies, TV-series are in English and with the help of the English language I can understand them fluently.

(4) It is very useful, I am sure I will need it in my job, with the help of it I can get to know citizens of different countries and I love travelling!

Answers to the question I will need English the most were:

- For Boys:

- In travelling/communicating with people: $55 \%$

- In the future occupation $35 \%$

- In free time/in hobbies $20 \%$

- For Girls:

- In travelling/communicating with people $65 \%$

- In studying $25 \%$

- In the future occupation $15 \%$

- For both sexes:

- In travelling/communicating with people $60 \%$

- In the future occupation $20 \%$

- In studying $10 \%$ 
As to the question How does school environment (teachers, examinations, etc) affect your motivation to study English?, comments of participants were:

- For Boys:

(5) The examination motivates, as well as good teachers.

(6) The constructive feedback from the teachers motivates to improve one's language proficiency, the exams tell the level of the language skills. The examination gives an idea on how to apply one's language skills in demanding situations.

- Girls went along with the boys about the importance of teachers and examinations, which can either reduce or increase the motivation towards English, as can be seen from girls' comments:

(7) A good teacher affects a lot. Exams, for example vocabulary tests make me study, because I want good grades.

(8) Some teachers increase, others reduce, exams reduce motivation, because I don't do as well in those as in lessons, the examination motivates the most at the moment.

To the question Which things outside school affect your motivation to study English and how?, Comments from participants went as follows:

- For boys:

(9) Foreign friends affect outside school, I communicate with them in English. Also many instructions and programmes use English. The occupation affects, too.

(10) The desire to be able to communicate fluently on the Internet. I watch programmes on the computer.

For girls, communication with foreigners, travelling, book-reading and watching movies and TVseries in English were most important:

(11) Discuss with my Nigerian friends, travelling abroad, understanding movies and TV-series.

\subsection{Motivation to Learn Spanish}

\subsubsection{Statements on Spanish}

Table2. Answers about Spanish (Note: 1 agree strongly, 2 agree somewhat, 3 neutral, 4 disagree somewhat, 5 disagree strongly)

\begin{tabular}{|c|c|c|c|c|c|c|c|}
\hline & & & \multicolumn{5}{|c|}{ Likert-scale (\%) } \\
\hline $\mathrm{N}^{\circ}$ & STATEMENTS & & 1 & 2 & 3 & 4 & 5 \\
\hline \multirow{3}{*}{1} & \multirow{3}{*}{$\begin{array}{l}\text { I am interested in the Spanish language and the cultures of Spanish - } \\
\text { speaking countries. }\end{array}$} & Total & 14 & 42 & 20 & 20 & 4 \\
\hline & & Girls & 20 & 44 & 20 & 16 & 00 \\
\hline & & Boys & 00 & 45 & 15 & 30 & 30 \\
\hline \multirow{3}{*}{2} & \multirow{3}{*}{$\begin{array}{l}\text { The Spanish language is important to me because I will need it in my } \\
\text { future occupation. }\end{array}$} & Total & 4 & 30 & 38 & 15 & 13 \\
\hline & & Girls & 5 & 33 & 48 & 7 & 7 \\
\hline & & Boys & 00 & 40 & 10 & 40 & 10 \\
\hline \multirow{3}{*}{3} & \multirow{3}{*}{$\begin{array}{l}\text { I am studying Spanish because I want to be able to communicate with } \\
\text { foreigners. }\end{array}$} & Total & 22 & 34 & 12 & 25 & 7 \\
\hline & & Girls & 22 & 40 & 11 & 22 & 5 \\
\hline & & Boys & 19 & 15 & 15 & 40 & 11 \\
\hline \multirow{3}{*}{4} & \multirow{3}{*}{ I am studying Spanish only because I have to. } & Total & 17 & 29 & 5 & 20 & 29 \\
\hline & & Girls & 16 & 16 & 6 & 22 & 40 \\
\hline & & Boys & 10 & 55 & 10 & 25 & 00 \\
\hline \multirow{3}{*}{5} & \multirow{3}{*}{ I will need Spanish in the studies after secondary school. } & Total & 14 & 35 & 35 & 11 & 5 \\
\hline & & Girls & 20 & 33 & 38 & 9 & 00 \\
\hline & & Boys & 00 & 40 & 30 & 7 & 23 \\
\hline \multirow{3}{*}{6} & \multirow{3}{*}{$\begin{array}{l}\text { I want to learn Spanish because many employers require Spanish } \\
\text { language skills. }\end{array}$} & Total & 23 & 38 & 32 & 7 & 00 \\
\hline & & Girls & 30 & 44 & 21 & 5 & 00 \\
\hline & & Boys & 9 & 32 & 50 & 9 & 00 \\
\hline
\end{tabular}

The majority of the participants (42\%) agreed somewhat with the claim "I am interested in the Spanish language and the culture of Spain". The usefulness of Spanish in working life is not very 
clear to the students, since $38 \%$ answered "neutral" to the question "The Spanish language is important to me because I am will need it in my future occupation". Most participants (34\%) agreed somewhat with the claim "I am studying Spanish because I want to be able to communicate with foreigners". The students both agreed and disagreed with the question "I am studying Spanish only because I have to". $29 \%$ of the participants agreed somewhat with this claim, whereas the same number of students disagreed strongly with the claim. Most students (35\%) agreed somewhat with the claim "I will need Spanish in the studies after secondary school", but as many students did not know or were not sure if they would need the language in future studies (35\% neutral). The question "I want to learn Spanish because many employees require Spanish language skills" was agreed somewhat by majority of the participants $(38 \%)$. No one disagreed strongly with this claim, but the percentage of "neutral" was high (32\%) in this question as well.

\subsubsection{Open-ended questions about Spanish}

Answers to the question Things that motivate to study Spanish the most were:

- For Boys:

- Communication with Spanish-speaking people $40 \%$

- The language itself $40 \%$

- Examination $40 \%$

- I need Spanish in working life $40 \%$

- I need Spanish in studies after secondary school $30 \%$

- For Girls:

- Communication with Spanish-speaking people $45 \%$

- The language itself $30 \%$

- It is important to know the language $25 \%$

- I need Spanish in working life $25 \%$

- Examination $20 \%$

- For both sexes:

- Communication with Spanish-speaking people 40\%

- The language itself $30 \%$

- I need Spanish in working life $25 \%$

- Examination $20 \%$

In short, communication with Spanish-speaking people, the language itself, the use of Spanish in working life and examinations are some of the most common motivators mentioned by participants. Comments on the importance of the Spanish language were:

- For boys:

(12) I want to prove that I know Spanish to the extent that I can pass the exams.

- Girls, on their part, think that they will need Spanish in studies and in working life. Their comments went as:

(13) One needs to know the language and be able to speak it fluently.

(14) I will certainly need it during my studies and in working life.

To the question I will need Spanish the most, the most common situations where the participants think they would need Spanish was travelling abroad and communicating with people, as it emerged:

- For Boys:

- Do not know $45 \%$

- In studying 35\%

- In travelling/communicating with people $30 \%$ 
- For Girls:

- In the future occupation $50 \%$

- In travelling/communicating with people 35\%

- In studying $25 \%$

The participants' comments for the question How does school (teachers, examinations, the examination) affect your motivation to study Spanish? were as follows for boys:

(15) The examination motivates as well as good teachers.

(16) Weak grades actually destroy my motivation. Teachers do not affect that much.

Girls answered the same question and emphasized success at school. Here are some of the answers given by girls:

(17) My friends perform well in Spanish, I also have to do well myself.

(18) Motivation comes from my own interest, so school does not affect it a lot. Maybe doing well in the examination motivates.

As to the question which things outside school affect your motivation to study Spanish and how? participants answered that communication with foreigners was one of the most commonly mentioned answers. Some students also stated that they do not use Spanish outside school. Boys' comments were:

(19) Spanish relatives and trips to Spanish, working opportunities.

(20) I do not use Spanish actually anywhere else at all except at school.

Comments from girls did not differ significantly from answers given by boys:

(21) Communication with other people and a prospective studying/living in Spain or in a Spanishspeaking area.

(22) I do not really need Spanish otherwise in everyday life.

\section{Discussions OF ReSUlts}

\subsection{Results in Relation to Integrative and Instrumental Motivation}

The vast majority of the participants were interested in the English language and the cultures of English-speaking countries. Almost three out of four also needed the language in communication with foreigners, which means that the motivation to learn English is largely integrative and the students are genuinely interested in the English language. Many students also wanted to continue studying English in the future and they realized the value and the importance of the language in their lives. Travelling and communication with people were clearly the most common reasons for studying English. Therefore, integrative motivation is strong among English language learners.

Following answers to questions about Spanish, integrative motivation seems not to be strong as in English. Half of the participants were interested in Spanish and the culture of Spain and they needed the language when communicating with people, but the other half did not have an opinion or they lacked interest in Spanish. Others pointed out they studied Spanish unwillingly and only because they had to, and they did not know if they need the language at all. In brief, integrative motivation among the participants is stronger in their studies of English than in studies of Spanish.

Instrumental motivation, on the other hand, is strong in the results of both languages. Actually, foreign language learners wish to get economic benefits and improve their social status by knowing foreign languages. The participants in this study were aware of the opportunities provided by languages as far as studies and working life is concerned since most of them said that they would need English and Spanish in their future occupation and many of them would need them in their studies as well. However, among the different reasons they listed for studying both languages, communication purposes and interest towards the language were more common than reasons related to studies and work. Thus, participants' motivation to learn both languages seems to be more integrative than instrumental. 


\subsection{Results in Relation to Intrinsic and Extrinsic Motivation}

As mentioned previously, intrinsic motivation is strongly linked to integrative motivation. Communication with relatives and other people is usually considered satisfying. Therefore, travelling and communication can also be viewed as intrinsic motives. Boys mentioned that they need English in free time and in their hobbies, so they must have intrinsic interest towards English.

All the participants have got a good grade in their previous English course, and as Malmberg and Little (2002: 136) claim, success at school increases students' intrinsic motivation. As to Spanish, a third of the participants said that the language itself motivates them in their studies.

Extrinsic motivation is often seen as an opposite to intrinsic motivation. Good grades are an example of extrinsic motives, and those were mentioned by several students in this study. For instance, exams and good grades were mentioned as school-related motives for studying English. When compared to other types of motivation, extrinsic motivation is not as strong as for instance integrative and instrumental motivation. In answers to questions about Spanish, on the other hand, the role of exams is stronger than in studies of English; for example, examination was more commonly mentioned as a thing that motivated the participants to study Spanish. Also other people affected the students' motivation to learn Spanish. Some students wanted to prove others that they knew the language. As a conclusion, extrinsic motivation seems to be stronger in studies of Spanish than in studies of English.

\subsection{Gender-Related Differences}

Most boys and girls who participated in the study had a genuine interest towards the English language. Both sexes agreed with the importance of English in communication and in their future because they need it to understand literature and TV-programmes. So the language is a condition for doing many things. More girls than boys answered that examination and good grades were important motivators for them to study English, so girls seem to be somewhat more extrinsically motivated to study English than boys. Many boys, on the other hand, are instrumentally motivated to study English because the language is valuable for them in their future occupation. This result correlates Virnes' (1995: 90, 116) findings, according to which instrumental motivation is strongest among boys.

As to Spanish, unlike girls, boys have weak opinions about the importance of Spanish. They seem to be very sceptical about the Spanish language and its role in their future lives. In effect, $40 \%$ of the boys know nowhere where they would need Spanish. More girls than boys wanted to study Spanish after secondary school, which means that girls appreciate Spanish more than boys. Both girls and boys emphasized the communicative value of Spanish and the language itself as their motivators, whereas boys also considered the examination and their future occupation as important factors as the previously mentioned ones, so their motivation to learn Spanish is intrinsic and also controlled by extrinsic factors and social demands.

\section{Conclusion}

This study intended to compare the motives of Beninese advanced learners to study Spanish and English as foreign languages. From the data collected, it emerged that participants were more interested in English than Spanish. Therefore, integrative motivation was stronger in studies of English. Participants' motivation to learn both languages is more integrative than instrumental. As to Extrinsic motivation, it emerged as stronger in the Spanish language than in English. The main differences between boys and girls appeared in extrinsic and instrumental motivation towards English: girls were slightly more extrinsically motivated to learn English than boys, and boys had more instrumental motivation towards English. In Spanish language learning, more girls than boys realize the value of Spanish in their lives and they know that they will need the language in future.

These findings could help both in-service and novice language teachers to realize that language learning motivation is complex and consist of different factors that affect the students' lives, such as exams, future orientation and communication with people. Further research is needed to examine variables that affect students' motivation and language learning at school, such as the socioeconomic situation of their parents. 


\section{REFERENCES}

[1] Banks, J.A. (2003). Educating global citizens in a diverse world. Retrieved from: http://www. newhorizons.org/strategies/multicultural/banks2.htm

[2] Brown, H.D. (1987). The principles of language learning and teaching. Englewood, N.J.: Prentice-Hall.

[3] Cresswell, J.W. (1994). Research design: qualitative and quantitative approaches. London: Sage.

[4] Crystal, D. (2001). A dictionary of language. Chicago: University of Chicago.

[5] Dörnyei, Z. (1994). Motivation and motivating in the foreign language classroom. The Modern Language Journal, 78 (3), 273-284.

[6] Dörnyei, Z. (2005). The psychology of the language learner: individual differences in second language acquisition. Mahvah, NJ: Lawrence Erlbaum.

[7] Gardner, R. and W. Lambert (1972). Attitudes and motivation in second-language learning. Rowley, Massachusetts: Newbury House publishers.

[8] Green, J.M. (1993). Student attitude toward communicative and non-communicative activities: Do enjoyment and effectiveness go together? The Modern Language Journal, 77 (i), 1-10.

[9] Heining-Boyton, A.L., \& Haitema, T. (2007). A ten-year chronicle of student attitude toward foreign language in the elementary school. The Modern Language Journal, 91 (ii), 149-168.

[10] Howatt, A.P.R. (2004). History of English language teaching. New York: Oxford University Press.

[11] Johnson, R.B., \& Onwuegbuzie, A. (2004). Mixed methods research: A research paradigm whose time has come. Educational Researcher, 33 (7), 14-26. 70

[12] Kouritzin, S.G., Piquemal, N.A., \& Renaud, R.D. (2009). An international comparison of socially constructed language learning motivation and beliefs. Foreign Language Annals, 42 (2), 287-317.

[13] Lichtman, M. (2010). Qualitative research in education: A user's guide. Thousand Oaks, California: Sage Publications.

[14] Littlewood, W. (2010). Chinese and Japanese students' conceptions of the 'Ideal English Lesson'. RELC Journal, 41 (1), 46-58.

[15] Malmberg, L.-E. (1994). Future-orientation of Finnish Students. Reports from the Faculty of Education, Åbo Akademi University. No. 1. Åbo: Åbo Akademi.

[16] Malmberg, L.-E. \& Little, T.D. (2002). Mikä meitä liikuttaa. Modernin motivaatiopsykologian perusteet. Keuruu: PS kustannus, 127-144.

[17] McKay, S. (2002). Teaching English as an international language. Oxford: Oxford University Press.

[18] Mertens, D.M. (2005). Research and evaluation in education and psychology: Integrating diversity with quantitative, qualitative, and mixed methods. Thousand Oaks, California: Sage Publications.

[19] Peacock, M. (1998). Exploring the gap between teachers' and learners' beliefs about 'useful' activities for EFL. International Journal of Applied Linguistics, 8 (2), 233-250.

[20] Price, J., \& Gascoigne, C. (2006). Current perceptions and beliefs among incoming college students towards foreign language study and language requirements. Foreign Language Annals, 39 (3), 383-394.

[21] Ryan, R.M. and E.L. Deci (2000). Intrinsic and extrinsic motivations: Classic definitions and new directions. Contemporary Educational Psychology, 25, 54-67.

[22] Savignon, S.J. (2002). Interpreting communicative language teaching: Contexts and concerns in teacher education. New Haven, Connecticut: Yale University Press.

[23] Silverman, D. (2000). Doing qualitative research: A practical handbook. London; Thousand Oaks, California: Sage Publications.

[24] Stemler, S. (2001). An overview of content analysis. Practical Assessment, Research \& Evaluation, 7 (17). Retrieved from: http://PAREonline.net/getvn.asp?v=7\&n=17 
Dr. TCHIBOZO LAINE Ida Marie Joséphine et al.

[25] Tse, L. (2000). Student perceptions of foreign language study: A qualitative analysis of foreign language autobiographies. The Modern Language Journal, 84 (1), 69-84.

[26] Virnes, A. (1995). A comparative study on motivational variables in foreign language learning. Unpublished Pro Gradu Thesis. University of Jyväskylä, Department of English.

\section{AUTHORS' BIOGRAPHY}

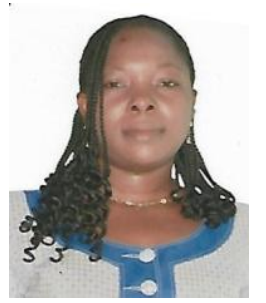

Dr. TCHIBOZO LAINE Ida Marie Joséphine, holds a doctorate degree in Applied Linguistics to Literature since 2016.

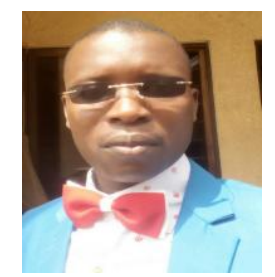

Dr. KAKPO Marcel, holds a doctorate degree in Applied Linguistics to Text Translation since 2016.

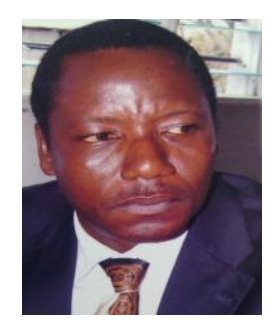

Dr. KPOHOUE Ferdinand, holds a doctorate degree in American Studies since 2012. He is currently the Head of Department of English Studies. FLLAC /UAC. 